To cite this article: Ruth O. Owolabi, Adebowale I. Ojo \& Chinyere N. Ikonne (2021) Influence of Information Behaviour and Perceived Risks on Substance Use of Undergraduates in Universities in Ogun State, Nigeria. Information Impact: Journal of Information and Knowledge Management, 12:1, 47-61, DOI: https://dx.doi.org/10.4314/iijikm.v12i1.4

To link to this article: https://dx.doi.org/10.4314/iijikm.v12i1.4

\title{
Influence of Information Behaviour and Perceived Risks on Substance Use of Undergraduates in Universities in Ogun State, Nigeria
}

\author{
${ }^{1}$ Ruth Onajite Owolabi \\ ${ }^{1}$ Adebowale Ifeoluwa Ojo \\ ${ }^{1}$ Chinyere Nkechi Ikonne \\ ${ }^{1}$ Department of Information Resources Management, Babcock University llishan-Remo, Ogun State, Nigeria
}

\begin{abstract}
This study investigated the influence of information behaviour and perceived risks on substance use among undergraduates in universities in Ogun State, Nigeria.The study adopted survey research design. The population comprised 82,809 undergraduates in 14 approved private, state and federal universities in Ogun State, Nigeria. Krejcie and Morgan table was used to determine the sample size of 1,513 undergraduates. A two-stage random sampling technique was used to select the respondents. A validated questionnaire was used for data collection. The Cronbach's alpha reliability coefficients for the constructs ranged from 0.89 to 0.99 . The response rate of $93.9 \%$ was achieved. Data were analysed using descriptive and inferential (multiple regression) statistics. Findings showed that information behaviour and perceived risks had no combined significant influence on substance use among undergraduates $\left(\right.$ Adj $\left.R^{2}=-.001, F(2,1417)=.627, p>0.05\right)$. Additionally, among other findings, it was discovered that information behaviour had a significant influence on substance use among the undergraduates $\left(R^{2}=.022, \beta=\right.$ $.149, t(1,414)=6.420, p<0.05$ The study concluded that information behaviour and perceived risks did not jointly influence substance use. However, both information behaviour and perceived risks, on individual basis influenced substance use. The study recommended that university management and stakeholders should intensify efforts to increase awareness programs to eradicate substance use on university campuses. Intervention from World Health Organization.
\end{abstract}

Keywords Information behaviour, Perceived risk, Substance use, Undergraduates

CONTACT Ruth O. Owolabi, Adebowale I. Ojo and Chinyere N. Ikonneowolabir@babcock.edu.ngi Babcock University IlishanRemo,Ogun State, Nigeria and Clifford University Library, Ihie, Abia State, Nigeria. 2021 The Authors Published with License by Information Impact 


\section{Introduction}

Undergraduates are students in universities undergoing an academic training that will lead to the award of degrees at the end of 4 to 6 years' programme depend on the course of study. University years are especially as undergraduate is characterized by independence that could result from the absent of much parental influence that may possibly allow for the indulgence of unhealthy practices. Some of the youthful exuberance exhibited by undergraduates are: cohabitation, malpractices, stealing, participation in cult, the abuse of substances and other vices that could hinder the accomplishment of a successful academic pursuit. The undergraduate years are sensitive one that opens students to lots of opportunities and freedom from parental guidance which when abused could possibly affect their future career. Observation of happenings in different university campuses and from news show that in Nigerian universities, the influx of substance in all the categories of university ranging from federal to state then to private has become an urgent public health issue of great concern that needed to be harness before it destroys the future generation of our nation.

Substances in this context are a group of psychoactive drugs used to stimulate human mental activity in a way that could alter the human wellbeing. According to Uchendu and Ukonu (2016), substances are drugs which when ingested, inhaled, or injected into the body have the potential to alter mood, behaviour and perception or mental functioning of an individual. Substances exist in different forms such as liquid, gaseous and in solid form which when sniffed, swallowed, injected, inhaled, drank, and chewed can alter the functions of the brain and the central nervous system. There are different types of substances available at the reach of undergraduates in universities in Ogun State such as codeine, tramadol, cocaine, and marijuana can be considered as illicit and injurious to human health. However, there are substances that can be regarded as legal but its use can produce the same adverse effect as the illicit substances and the examples of such substances are nicotine, alcohol, caffeine, and tobacco. All the considered licit substances are available in virtually all the corner shops around university campuses and in the open market. The availability of the different substances in different universities could result in the experimentation of some of the substances by undergraduates in the different levels of universities.

Despite the publicity on the mass and print media by the government and non-governmental organisation to inform the public on the hazard and implication of substances to the health and people in the university environ at large, undergraduates in Nigeria tend to buy and use these illegal substances, hence this study investigates the influence of information behaviour and perceived risks on substance use of undergraduates in universities in Ogun State, Nigeria.

Substance use among undergraduates in universities is one of the prevalent global health issues of great concern that affects their total wellbeing and academic performance. Substance use still persists in the society today, most especially in the university campuses. However, students who indulge in substances are exposed to risks that could be resulting in different medical conditions, addiction and harm to oneself and others. Despite the important role that information plays in exposing the risks associated with substance use, substance use still persists. This could be attributed to their inability of students to recognise the needed information required to address the problem of substance use and the associated risks. Empirical works exist in support of perceived risks and substance use among undergraduates but it is not apparent that a study in Ogun State, Nigeria has addressed the influence of information behaviour and perceived risks on substance use. This study, therefore, investigated the influence of information behaviour and perceived risks on substance use among undergraduates in Ogun State, Nigeria. 


\section{Objective of the study}

The main objective of this study is to investigate the influence of information behaviour and perceived risks on substance use among undergraduates of universities in Ogun State, Nigeria.The specific objectives are to:

1. determine the influence of information behaviour on substance use among undergraduates in universities in Ogun State;

2. examine the influence of perceived risks on substance use among undergraduates in universities in Ogun State and

3. ascertain the joint influence of information behaviour and perceived risks on substance use among undergraduates in universities in Ogun State, Nigeria.

\section{Hypotheses}

The following null hypothesis were tested at 0.05 level of significance.

H1 information behaviour does not significantly influence substance use among undergraduates in Ogun State.

$\mathrm{H} 2$ perceived risks do not significantly influence substance use among undergraduates in Ogun State.

H3 Information behaviour and perceived risks do not have joint significant influence on substance use among undergraduates in Ogun State..

\section{Literature review}

According to Chendu and Ukonu (2016) substances are drugs which when inhaled, ingested or injected into the body have the potential to alter the mood, behaviour, perception or mental reasoning of the person. There are substances most commonly used among undergraduates in Nigerian universities that are affirmed by Bello and Owoaje (2010) to be alcohol and tobacco. The excessive use of alcohol will possibly lead to slurred speech, unsteady movement, poor perception and redundancy in the brain functions. Tobacco has also been identified as one of the commonly used substances by students because it is attractive, affordable and accessible for easy purchase (Yusuf, 2012).

Tobacco use would likely cause lung cancer, tuberculosis, abortion to a pregnant woman and harm to people around who indirectly become second hand smokers. Tobacco is one of the leading causes of death among young people. Tobacco are smoked, chewed, snuffed, and sucked. Tobacco leaf is processed into cigarette, cigar, cannabis cigarette and pipe tobacco. Statistics reveal that 7 million people die as a result of direct smoking of tobacco while 1.2 million non-smoker fall victim of second hand smoking (WHO, 2019). Smoking cigarette which is one of the most popular product of tobacco used by young people as a result of peer influence, environmental, parental upbringing. Smoking tobacco exposes the smokers to health complications like heart disease, high blood pressure, stroke, chronic obstructive airways disease, cancer of different types, premature ageing and wrinkling of the skin, bad breath, unpleasant odour on the hair and body as a result of the smoke. In addition, complication in pregnancy and low birth weight can occur. Thus, smoking can increase heart rate, cardiovascular diseases, lung diseases, respiration and blood pressure.

Alcohol is one of the well-known psychoactive substances known to affect the mood and the mental state of an individual. Alcohol use among undergraduates and other citizens results in health conditions that expose the users to several health risks. Ekpenyong and Aakpege (2014) revealed that alcohol use among university students has become a serious public health issue in Nigeria. The abuse of alcohol could be as a result of its availability at the reach of the public and because it is considered acceptable in some occasions as such many young people misuse it. Alcohol use by undergraduates can 
alter the brain function and produce adverse effect on the central nervous system. According to Omigbodun and Babalola (2004), "Alcohol and cigarette are considered as gateway substances because they are the initial substance used before other ones such as marijuana and cocaine" (p.111). Alcohol contains ethanol produced from the fermentation of grains, fruit with sugar which when taken excessively can lead to addiction or drunkenness. Undergraduates tend to use other substances such as marijuana, cocaine, and opioid without considering the associated consequences on their total wellbeing. Marijuana also known as cannabis is one of the legally prohibited substances around the world. In Nigerian universities the name weed, loud, shisha, colorada synthetic and black mamba is used among undergraduate to refer to marijuana. Akande (2018) discovered a new deadly form of marijuana known as synthetic and black mamba as slowly wreaking Nigeria's cities by causing mental episodes, hallucination, convulsions, kidney failure and 'zombie-like' state of intoxication leading to death. Cannabis is one of the illegal substances that the youths are using since it is perceived to be of little harm by many (Awosusi \& Adegboyega, 2013). According to Akanbi, Godwin, Anyio-Bahago, Muhammad, and Ajiboye (2015),

'undergraduates discourteously depend on one form of substance or the other

for their various daily activities such as social, educational, political, and moral

so is the use of substances such as tobacco, Indian hemp, cocaine, morphine,

heroine, alcohol, epherdrine, caffeine, glue, and barbiturates" (p. 109).

Some of the consequences of marijuana use among young people can develop into acute psychosis which is a severe mental disorder that make an individual have uncoordinated thought. In addition, hallucination, loss of sense of personal identity, Schizophrenia, brain tumour and delusion are possible health conditions that could result from marijuana use (WebMD, 2019).

Cocaine which is also known as coke is another substance abused by many youths around the world and is produced from a coca plant (Erythroxylin coca). Cocaine is strongly and highly addictive substance made from the leaves of coca plant that is mostly cultivated in South America (Drug Abuse, 2016). In addition, chewing of coca leaf, a substance in which cocaine is found can lead to permanent functional brain damage resulting in a cognitive deficit (WHO, 1987). Cocaine use can harm human health as it causes life threatening diseases that can lead to severe brain damage. Cocaine users develop tolerance and the relative risk for addiction is high (Katzung, 2012). Anyone who engage in cocaine use have the prospective of becoming an addict as such placing the individual at a perceived risk of addiction if formed as habit.

Opiate is synonyms to opioids. Opiate is an analgesic used in clinical treatment of moderate to severe pain and derived from opium poppy plant. Opioids are a class of drugs that include the illicit drug like heroin as well as the licit prescription pain relievers oxycodone, codeine, morphine, fentanyl and tramadol (National Institute on Drug Abuse, 2015). In Nigeria prescribed group of opiate like tramadol, codeine, pentazocine and others are abused drugs (UNODC, 2015). Opioids are among abused substances that affect the effective functioning of the central nervous system that coordinate the activities of the whole body. Opioids use triggers substance use disorder that increases the risk of relapse, also, increasing the risk of relapse significantly lead to the presence of existing psychiatric (Semulimi, 2017).

Substance use is referred to as the use of psychoactive drugs applied without prescription by the physician. Media report of National Drug Law Enforcement Agency [NDLEA] (2017) reveals that 60\% of Nigerian youth have one time or the other tasted substance. This shows the prevalent rate of substance use in Nigeria as a whole without any discrepancy in geographical location. Substance abuse is the result of excessive substance use according to (NDLEA, 2017), the abuse of substance by students in schools, colleges and universities in Nigeria is a major problem. Onafa, Adamson, Ighoroje, and Majekodunmi (2016) in their study of prevalence and pattern of drug abuse among students of tertiary institutions in 
Ogun State, Nigeria discovered that the lifetime prevalence of use for one or more drugs leading to abuse is $69.2 \%$. The highest lifetime prevalence rates for alcohol $34.3 \%$, tobacco $14.4 \%$, hypnosedatives $8.8 \%$ and cannabis $6.2 \%$. The substances use could be for several reason of which can be to fulfil the urge to experiment as it is part of undergraduate way of life, taste and have a sense of belonging. undergraduate tend to be vulnerable to substance use because of peer pressure, environmental influence, and family upbringing, without adequate information of the risks associated with its use. According to Adekeye (2012), it has been discovered that undergraduate in Nigeria experiment with drugs without good understanding of the drug to take and how to take it. It is based on this that students in Nigeria tertiary institutions seem to be involved in substance use which has effect on their health and academic performance.

The use of substance among undergraduates can be traced to the habit formed from primary and secondary schools. In addition, Okoza and Aluede (2009) find out that "much of the substance use among youths takes place in schools" (p.87). According to Alhyas et al (2015), teenagers were found to be involved in substance use at an early age of 11 and 14 years. This could be that the teenagers are exposed to substances at a tender age in their family and the environment of upbringing. Sue, Sue, and Sue (2006) owned that the increasing use of substances was discovered first in the developed world. This trend moved to the developing world in which undergraduates in use of substance was on the increase. Substance use could be traced to adolescents in secondary schools who advanced to tertiary institution and continued with it. It this possibly had led to the use of substances among undergraduates that has exposed young people to health, addiction and risk of harm to oneself and others at an early age.

It has been observed from past studies that in many public universities in Nigeria, there have been incessant students' unrests, riots, crimes, cultism, many of which are linked to substance use and drug abuse (Yusuf, 2012). This recorded evidence show that young people are laid to their early grave for the use of substances. Report from United Nations' 2016 World drug estimated that 1 in 20 adults, or a quarter of a billion people between the ages 15 and 64 years used at least one psychoactive drug in 2014, and over 29 million people worldwide suffer from drug use disorder (WHO, 2016). All these atrocities committed by undergraduates will possibly result in drawback in academic performance. Some of the factors that contribute to substance use among young people especially undergraduates are peer influence, curiosity and desire for adventure which could as well lead to the experimentation with substance (Johnson, Akpanekpo, Okonna, Adeboye, \& Udoh, 2017). Perception of risk associated with substance use differs from one individual to another.

Perceived risk is the individual judgment of harm and potential consequences that might arisefrom the use of substances among undergraduates in universities in Ogun State. According to Salzbergers and Cano (2017), perceived risk is referred to as a complex and multidimensional and hypothetical construct that captures the individual assessment of the potential consequences of product use. Perception of risk associated with substance use varies from one person to the other. Some undergraduates perceive greater risk of harm in substance while others do not. Youths who perceive high risk of harm are less likely to use drugs than youths who perceive low risk of harm (Johnston, O'Malley, Bachman \& Schulenberg, 2012).Some surveys done by different research institutes show that the perceived risk of harm from drug involvement has been declining while the availability of drugs has been rising (National Institute on Drug Abuse [NIDA], 2015); Substance Abuse and Mental Health Services Administration [SAMHSA], 2000). The study established that the youths' perception of risk of substance use is declining meanwhile the availability of substance is on the increase. This makes undergraduates not to view substance as harmful although the positive aspect of risk taking remains, the negative consequence cannot be underestimated. Morbidity and mortality in youth are related primarily to risk behaviour rather than to disease (Institute of Medicine [IOM] \& National Research Council [NRC], 2013). 
Chrea, Emilien, Salzberger, Cano, Alfieri, and Lüdicke (2015) developed an instrument to measure the perceived risk associated with the use of Nicotine and tobacco products. The three main domains in the perceived risk instrument are health risk, addiction risk and harm to others. The Perceived risk instrument (PRI) developed a final conceptual framework to include two main domains, which are health risk to self that is an independent one-dimensional scale with 18 items and perceived health risk, with 7 items perceived addiction risk and two global items assessing harm to others (Chrea, et al., 2015). Another instrument is the one developed by Salzberger and Cano (2017) on the perceived risk of tobacco use with emphasis on the consumer perception of product risks and benefits. The perception of risk is dependent on the individual awareness of the health hazards associated with substance use. Information received and rightly applied should inform undergraduates on the health consequences and harm that can result in substance use. Information is expedient in every facet of human existence as such children, young, and old require it for good decision-making especially as relate to substance use. In attempt to curb the global health menace of substance use among undergraduates there is need to develop good information behaviour. Information behaviour is regarded as the undergraduate attitude towards the search for the right information. The health risk emphasises the disease one can be exposed to when overtaken with substances and the likely effect one's psychological and mental wellbeing. Health risk highlight the possible health hazards one exposes the health to when involved in substance use at a youthful age and the effect on the future health of the individuals involved. Possible health risks undergraduates can get from substance use are: bad cough that last several days, heart disease, poor gum health, lung cancer, blurred sight, occasional wheezing, mouth and throat cancer, aging faster, frequent illness, respiratory infection, reduced stamina, poor taste bud, physically unfit, sore in the mouth and throat with untimely death. Some of the substances use that result from the aforementioned are smoking cigarettes and cannabis, inhaling and injecting cocaine to the body, drinking of alcohol and opioids like nicotine, codeine, tramadol can result in health risk.

Addiction is the persistent urge to use substances like alcohol, tobacco, cannabis, cocaine, and opioids despite the adverse effect on health. Addiction risk is the consequences associated to substances that are injurious to the health of undergraduates' who have become used to and cannot do without substances affect the psychology of the involved persons. Addiction risk may result from excessive and frequent use of all the substances like alcohol, tobacco, marijuana, cocaine, and opiate which leads to lifetime chronic and psychological conditions. Addiction risk can result in the excessive intake of substance on a daily basis which results in brain disorder affecting all the central nervous system functions. Finally, the process of substance use among undergraduates can lead to harm to oneself and others. Perceived risk of harm to oneself and others that can result in the continuous use of the substance that might lead to lifetime harm to oneself and others in the case of abortion of pregnant women and violent act among undergraduates. They can also harm others for instance, when undergraduates are involved in smoking of any of the substances, people in the environment are automatically made second hand smokers which have the same health effect as the first hand smokers. In addition, a pregnant woman involved in drinking alcohol and smoking cigarette will endanger the unborn child to death. alcohol during pregnancy. The harm to others can possibly result in violent acts among undergraduates in universities such as, sexual assaults like rape, and accident of any kind.

\section{Information behaviour}

Information behaviour is the act of individual to intentionally identify a gap (need), locate relevant information sources to fill the knowledge gap and utilised the suitable information acquired to make timely decisions. Information behaviour is defined by Wilson (1999) as the "the totality of human behaviour in relation to sources and channels of information, including both active and passive information-seeking and information use" (p. 249). Wilson stated that information behaviour 
encompasses the intentional information seeking as well as unintentional information encounter. Information behaviour of undergraduates can be divided into three (4) major components such as the recognition of information need, information seeking patterns, information sources and information utilization. Pettigrew, Fidel, and Bruce (2001) buttress these points, hence, this study was hinged on the recognition of information need, information seeking pattern, information sources and information use. Information behaviour was broken down into the different constructs to enable it play out well with the variables used in the study. The breakdown will help establish a relationship between the variables. Recognition of need will be used in this study because it reflects the behaviour of a person that identify the need to fill the gap in knowledge contrary to other studies that use information need. Recognition of information need is an individual's conscious or unconscious requirement to fill a gap in knowledge.

Information seeking is the process of recognising and interpreting problem thus, drawing a search plan, to evaluate the outcome by going over the processes again if necessary. Information seeking is unavoidably an indispensable precondition to consistent and suitable performances of these behaviours (Ek \& Heinstro, 2011). Young people seek information from social media, peer, internet, print and nonprint, formal and informal conversation from friends among others. Information seeking is the desire to search for adequate information to fill a knowledge gap. Ford (2015) established that informationseeking strategies adopted by an individual have been grouped into browsing and monitoring. The browsing may require the use of hardcopy or online resources while the monitoring could be through selective dissemination of information where those who need discover and provide access to specific individuals' information need. Information seeking is not complete without good information sources to accomplish the search process as such this study will incorporate information seeking with information sources.

Information sources are materials that contain information and can be referred to when there is need. Information sources exist in different forms, which could be print or non-print. In essence, information sources as defined by Adomi (2012) are "materials from which people receive ideas, meaningful messages, enlightenment and direction that will enable them to accomplish tasks, take decisions and solving problems" (p. 83). The use of the information sources can possibly lead to the awareness of the risk associated with substance use. Undergraduates consult several sources of information especially on health, sex, education, substance use among others. Other information sources that exist which undergraduates' likely consult are in media form including magazines, television and advertising, leaflets, books and websites (Fauzi \& Abd Kadir, 2015). Baheiraei, Khoori, Foroushani, Ahmadi, and Ybarra (2014) carried out a study on what sources adolescents turn to for information about their health concerns; it discovered that mothers $51.11 \%$ and same sex friends as $40.11 \%$, are the two primary sources well-preferred health information for adolescents. More than one in three adolescents identified media information sources, including books $39.6 \%$ and the internet $37.9 \%$, as their primary sources. It is essential to use information appropriately to solve the problem of substance use.

Information use occurs when undergraduates acquire the right information to satisfy a pressing need and take appropriate decisions. According to Wilson (2000), information use involves physical and mental capabilities to be able to integrate newly acquired information into the person's already existing knowledge database. Information use outcome is expected to satisfy information need and solve existing problem. Adequate information is expected to expose undergraduates to all the risk involved in substance use such as the perceived risk of health, addiction and harm to others thus, this study is expected to proffer possible solutions and means of abstinence. Undergraduates require adequate information behaviour to be able to take responsibility of handling life threatening issues like making use of substance and avoiding the likely consequences of perceived risk involved in substance use. The recognition of information need by undergraduates deal with the filling of gap in knowledge, which cannot be accomplished in vacuum but with the use of the right information sources made available in 
print and non-print format to enhance easy access. Despite, the effort of governments', nongovernments', policy makers and parents to cub the use of substances among undergraduates, there seems to be a lacuna that is required to be filled to reduce the menace of substance use among undergraduates. It is based on thefore going that this study investigated the influence of information behaviour and perceived risk on substance use among undergraduates in Ogun State, Nigeria.

\section{Methodology}

The study adopted survey research design. The design allowed the researcher to elicit data from respondents to investigate the influence of information behaviour and perceived risk on substance use among undergraduates in universities in Ogun State, Nigeria. The population of the study comprised 82,809 undergraduates in the universities in Ogun State. The population was made up of undergraduates of universities from the approved fourteen privates, states, and federal universities in Ogun State, Nigeria. Sample is a subset of a population. Krejcie and Morgan's (1970) Table was used to arrive at the sample size of 1,513 undergraduates at 0.025 Margin of error at $95.0 \%$ confidence level. In selecting the 1,513 sample size needed for the study, a two stage random sampling technique was adopted. In the first stage, total enumeration technique was used in selecting all the categories of universities that included privates, states, and federal universities. In the second stage, a simple random sampling technique was used to select $1.83 \%$ of students from each institution. The main instrument for the study were structured and adapted questionnaire to elicit data from respondents. The structured portion of the instrument was on the variable information behaviour that had 4 indicators which are recognition of information need, information seeking pattern, information sources and information use. The adapted portion from European School Survey Project on Alcohol and other Drugs [ESPAD], 2015 on substance use and perceived risk questionnaire was adapted from Chrea (2015) chart on perceived risk instrument to measure perceived risks associated with nicotine and tobacco products. Data collected from the field were examined for completion, coded and analysed using descriptive and inferential statistics. The research questions were analysed using descriptive statistics such as percentage, frequency distribution, mean and standard deviation. The hypothesis was tested at 0.05 significant level using inferential (Multiple regression) statistics. The analyses were done with the aid of statistical software package named Statistical Package for Service Solution (SPSS) version 25.

\section{Hypotheses testing}

Three null hypotheses were tested at 0.05 level of significance

$\mathbf{H}_{\mathrm{O} 1}$ : Information behaviour does not significantly influence substance use among undergraduates in Ogun State. 
Table 1 Regression analysis of information behaviour on substance use

\begin{tabular}{lllll}
\hline Variable & Sum of & df & Mean \\
Square & & Square & Sig.
\end{tabular}

$\begin{array}{lcclll}\text { Regression } & 5.943 & 5 & 1.189 & 6.420 & .000 \\ \text { Residual } & 267.791 & 1414 & .185 & & \\ \text { Total } & 267.733 & 1419 & & & \end{array}$

$\mathrm{R}=.149 \quad \mathrm{R}$ Square $.022 \quad$ Adjusted $\mathrm{R}$ Square $=.019$

Table 1 shows the linear regression analysis of the influence of information behaviour on substance use. The findings reveal that information behaviour significantly influence substance use among the undergraduates when $\mathrm{R}$ value $=.15, \mathrm{~F}_{5.1418}=6.42, \mathrm{P}<0.05$. Since the $\mathrm{P}$ value is less than 0.05 , it therefore means that information behaviour has significant influence on substance use as such information behaviour accounts for only $2.2 \%$ of the variance in the substance use. It is very low meaning other factors were responsible for about $97.8 \%$ for what could bring about change in substance use.

Table 2 Relative contribution of information need, seeking pattern, sources used, frequency of sources used, and use on substance use.

\begin{tabular}{|c|c|c|c|c|c|c|}
\hline \multicolumn{7}{|c|}{ Coefficients } \\
\hline \multicolumn{2}{|c|}{ Model } & \multicolumn{2}{|c|}{$\begin{array}{l}\text { Unstandardised } \\
\text { Coefficients }\end{array}$} & \multirow{2}{*}{$\begin{array}{c}\begin{array}{c}\text { Standardised } \\
\text { Coefficients }\end{array} \\
\text { Beta }\end{array}$} & \multirow[t]{2}{*}{$\mathrm{T}$} & \multirow[t]{2}{*}{ Sig. } \\
\hline & & B & $\begin{array}{l}\text { Std. } \\
\text { Error }\end{array}$ & & & \\
\hline & (Constant) & $\begin{array}{r}1.25 \\
4\end{array}$ & .044 & & 28.281 & .000 \\
\hline & Information Need & .009 & .013 & .022 & .660 & .509 \\
\hline & Information Seeking Pattern & .051 & .016 & .115 & 3.084 & .002 \\
\hline & Information sources consulted & -.096 & .020 & -.195 & -4.708 & .000 \\
\hline & $\begin{array}{l}\text { Frequency of information } \\
\text { sourcesused }\end{array}$ & .055 & .018 & .116 & 3.035 & .002 \\
\hline & $\begin{array}{l}\text { Information Use } \\
\text { ependent Variable: Substance Use }\end{array}$ & -.024 & .017 & -.054 & -1.418 & .157 \\
\hline
\end{tabular}

Table 2 provides the relative contribution of each indicators of the variables. Furthermore, the standardised beta coefficients show that information seeking pattern $(\beta=.051, \mathrm{p}<0.05)$, frequency of information sources used $(\beta=.055, \mathrm{p}<0.05)$ and information sources used $(\beta=-.096, \mathrm{p}<0.05)$ relatively contribute to substance use. Information need $(\beta=.009, \mathrm{p}>0.05)$ and information use $(\beta=-$ $.024, \mathrm{p}>0.05)$ do not relatively contribute to substance use. Therefore, the null hypothesis was rejected as information behaviour has a significant influence on substance use among undergraduates in Ogun State. 
$\mathbf{H}_{\mathrm{O} 2}$ : Perceived risks does not significantly influence substance use among undergraduates in Ogun State.

Table 3 Regression analysis of perceived risk on substance use

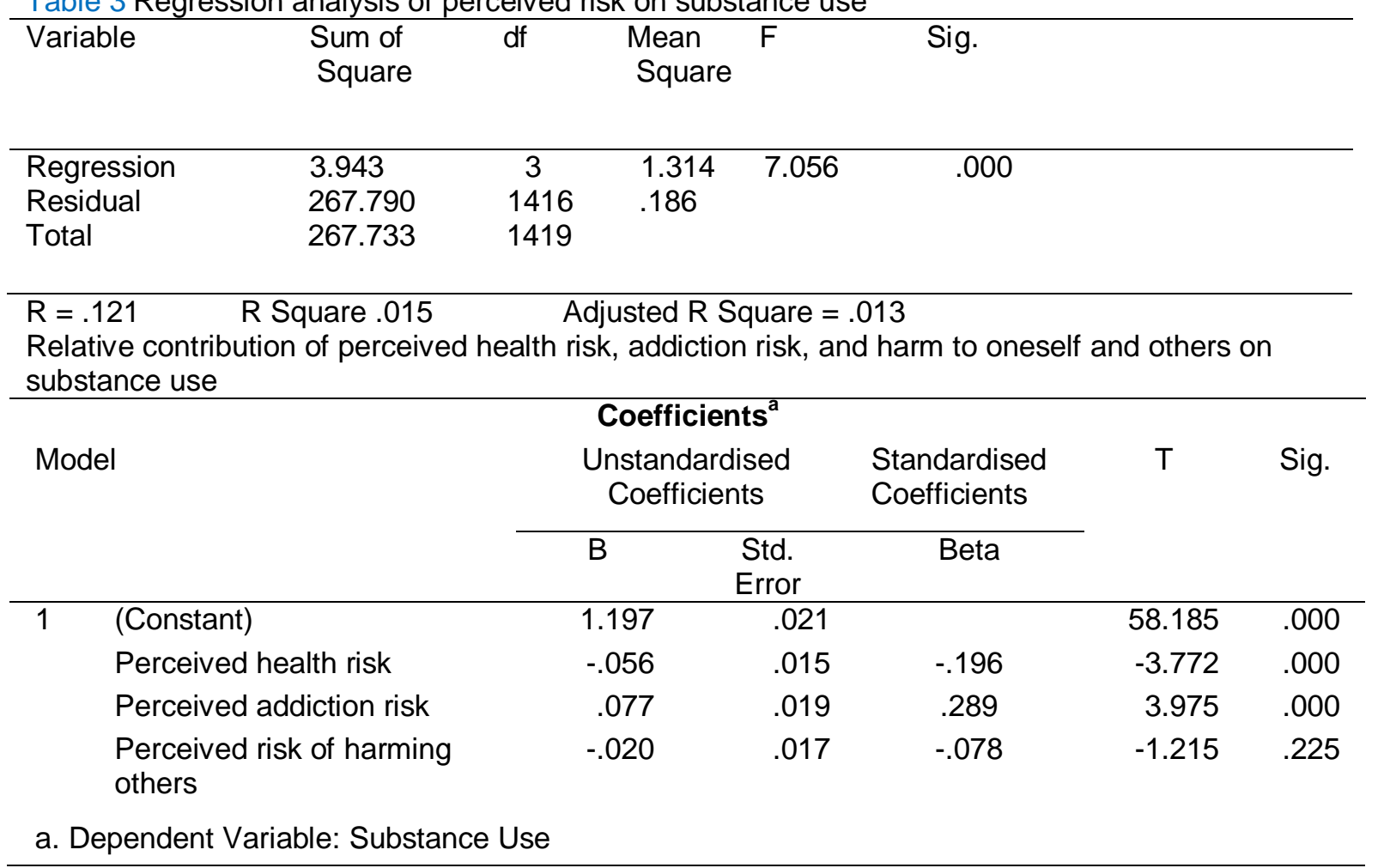

Table 3 shows the linear regression analysis of the influence of perceived risk on substance use. The findings show that perceived risk significantly influence substance use among the undergraduates when $\mathrm{R}$ value $=.12, \mathrm{~F}_{3.1416}=7.06, \mathrm{P}<0.05$. The study shows that perceived risk is responsible for only $1.5 \%$ of the total variance in substance use. It is very low which means that there were other factors responsible for about $98.5 \%$ of what brings about a change in substance use. Furthermore, the standardised beta coefficients show that perceived addiction risk $(\beta=.077, \mathrm{p}<0.05)$ and perceived health risk $(\beta=-.056$, $\mathrm{p}<0.05)$ relatively contribute to substance use. Perceived risk of harming others $(\beta=-0.02, \mathrm{p}>0.05)$ does not relatively contribute to substance use. Therefore, the null hypothesis was rejected as perceived risk significantly influence substance use among undergraduates in Ogun State. 


\section{$\mathrm{H}_{03}$ : Information behaviour and perceived risks does not have a joint significant influence on substance use among undergraduates in Ogun State.}

Table 3 Regression Analysis of Information Behaviour and Perceived Risks on Substance Use

\begin{tabular}{|c|c|c|c|c|c|c|c|c|c|}
\hline Variable & $\begin{array}{l}\text { Sum of } \\
\text { Square }\end{array}$ & df & $\begin{array}{l}\text { Mean } \\
\text { Square }\end{array}$ & $\mathrm{F}$ & B & $\begin{array}{l}\text { Std. } \\
\text { Error }\end{array}$ & $\begin{array}{l}\text { Coeff. } \\
\text { Beta }\end{array}$ & $\mathrm{t}$ & Sig. \\
\hline Regression & .237 & 2 & .118 & .627 & & & & & $.534^{\mathrm{b}}$ \\
\hline Residual & 267.497 & 1417 & .189 & & & & & & \\
\hline Total & 267.733 & 1419 & & & & & & & \\
\hline Constants & & & & & 1.214 & .044 & & 27.650 & .000 \\
\hline Information & & & & & -.012 & .016 & -.021 & -.734 & .463 \\
\hline Perceived R & & & & & .008 & $8 \quad .008$ & 3.030 & 1.049 & .294 \\
\hline
\end{tabular}

$\mathrm{R}=.030 \quad \mathrm{R}$ Square $.001 \quad$ Adjusted $\mathrm{R}$ Square $=.001$

Table 4 reveals the joint significant influence of information behaviour and perceived risks on substance use. The result showed that there were no joint significant influences of information behaviour and perceived risk on substance use when the $\mathrm{R}$ value $=.03, \mathrm{~F}_{2,1417}=.627, \mathrm{P}>0.05$. This study reveals that information behaviour combined with perceived risk will not influence undergraduates to use substances.

\section{Discussion of findings}

The first hypothesis examines the significant influence of information behaviour on substance use among undergraduates in Ogun State, Nigeria. This study reveals that information behaviour significantly influence substance use among undergraduates in Ogun State, Nigeria. This study hinged information behaviour on recognition of information need, information seeking pattern, information sources and information use. The study's findings reveal that undergraduates' recognition of information need on substance use is lower since undergraduates in universities in Ogun State do not take substances they did not recognise the information need on how to quit substance. However, health consequences of substance use, location on where to get substance and measures to reduce substance use was the information sought. Furthermore, findings on information seeking pattern reveal that undergraduates in Ogun State, Nigeria agree on having good information seeking pattern especially on the negative effect of substance use on the wellbeing of undergraduates and ways to avoid peer influence on substance use. The findings also reveal that they seek information on measures to quit the different substances common among the undergraduates in Ogun State, Nigeria.

The findings on frequency of information sources use reveals that internet, friends and social media had the highest frequency of use followed by television, family and relative, and books with seminar/conferences having the lowest consulted sources. More than one in three adolescents identified media information sources, including books $39.6 \%$ and the internet $37.9 \%$, as their primary sources. The study also reveals information use by undergraduates to abstain from either prescribed or non-prescribed substances, prevent from becoming a drug addict, create awareness on substance use and avoid the harm of socialising with drug addicts. This study reveals that information behaviour significantly influenced 
substance use which could result from the awareness on the implication of the different substances such as alcohol, tobacco, cannabis, cocaine and opioids.

The second hypothesis examined the influence of perceived risks on substance use among undergraduates in Ogun State, Nigeria. The study indicates that perceived risks significantly influenced substance use among undergraduates. Salzbergers and Cano (2017) regarded perceived risks as a complex and multidimensional and hypothetical construct that captures the individual assessment of the potential consequences of product use which could be substance use. The study findings show that one's awareness of the perceived health risk and perceived addiction risk will influence substance use while perceived harm to oneself and others do not significantly influence substance use. This study discovered that perceived risks either high or low do not have any influence on substance use, this implies that what one undergraduate perceives as health and addiction risk will determine the use of the different substances like alcohol, tobacco, marijuana, cocaine, and opioids. Undergraduates do not perceive the risk of harm to one self and others as reasons not to use substances like as alcohol, tobacco, marijuana, cocaine and opioids.

Highest perceived risks of alcohol and illicit drugs were found among abstainers and experimental alcohol consumers, while experimental and regular drug users tend to perceive a lower risk. Regular alcohol consumers perceive relatively high risks of illicit drug use, but they underestimate the risks of alcohol consumption. Perceived risks could possibly determine the use of substance to a great extent, individual perception of risks and it influences varies. This study finding aligns with the statement by Johnston, O'Malley, Bachman and Schulenberg (2012) that youths who perceived high risk of harm are less likely to use drugs than youths who perceived low risk of harm. It is expected that one's perception of risk will limit substance use. The study established that perceived risks influence on substance use this implies that your perceived risk of health and addiction will influence on alcohol, tobacco, marijuana, cocaine and opioid use among undergraduates. This result of this study affirms the findings of a study by National Survey on Drug Use and Health [NSDUH] (2012) which was conducted on the changes overtime in the prevalence of substance use and perception of risk and discovered that increase in substance use is a direct result of decrease in perception of risk. This study did not reveal high prevalence of substance use among undergraduates in Ogun State, Nigeria.

The third hypothesis examined the combined influence of Information behaviour and perceived risks on substance use. The result from the hypothesis confirmed that there is no combined influence of the two independent variables (information behaviour and perceived risks) on the dependent variable (substance use). The findings reveal that there is no combined influence between information behaviour and perceived risks on substance use by undergraduates in Ogun State, Nigeria. Although, information behaviour influences substance use, and perceived risks influence substance use but there is no combined influence of the two independent variables with the dependent variable.

\section{Conclusion}

The findings of the study show that information behaviour play an important role in exposing the risks associated with substance use among undergraduates as such it is important for undergraduates to be conscious of any decision made on substance use. Good information behaviour will help undergraduates decide either to use or not to use substances. It is expedient for undergraduates to be informed that heart disease and lung cancer are the major health risks one can be exposed to therefore sensitisation programme should be organised regularly on the perceived health risk of substance use. Introducing and implementing measures to control the risks associated with substance use such as creating advisory student support programmes could help create awareness to limit substance use. This could help in promoting healthy lifestyle and good academic performance of undergraduates. 


\section{Recommendations}

Based on the findings of this study, the following recommendations are offered:

1. Nigerian government and non-government organisations should increase the sensitization programmes on substance use in all the universities in order to promote total eradication of substance use among undergraduates.

2. The universities administrators should ban the sales and use of substances in university campuses and informing each undergraduate on the associated risks thus creating a conducive learning environment.

3. There should be regular awareness programmes on different electronic and non-electronic media which could exist in print and non-print sponsored by governmental and non-governmental organisation to provide timely information to young people especially undergraduates through the varied sources to expose the implications of substance use.

4. The universities administrators should seek the intervention of World Health Organisation (WHO), National Drug Law Enforcement Agency (NDLEA), governmental and nongovernmental organisation in establishing affordable welfare and rehabilitation centres (to cater for the few who still use substance) within the universities.

\section{References}

Adomi, E. E. (2012). Information sources in the humanities. Benin City: Ethiope Publishing Corp.

Akanbi, M. I., Godwin, A., Anyio, B. T., Muhammad, M., \& Ajiboye, S. A. (2015). Impact of substance abuse on academic performance among adolescent students of colleges of education in Kwara State, Nigeria. Journal of Education and Practice IISTE, 6(28), 2222- 288X.

Akande, S. (2018, 05). A new deadly form of marijuana is slowly wreaking havoc in Nigeria's cities. Retrieved from Pulse Nigeria Web Site: https://m.guardian.ng/features/education/stakeholdersdiffer-on-age-limit-for-university-admission/

Alhyas, L., Al Ozaibi, N., Elarabi, H., El-Kashef, A., Wanigaratne, S., Almarzouqi, A., \& Al Ghaferi, H. (2015). Adolescents' perception of substance use and factors influencing its use: a qualitative study in Abu Dhabi. Journal of the Royal Society of Medicine Open, 6(2), 1-12.

Awosusi, A. O., \& Adegboyega, J. A. (2013). Knowledge of health effects and substance use among students of tertiary institutions in South-Western, Nigeria. Journal of Education and Practice, 4(23), 2222-288X.

Baheiraei, A., Khoori, E., Foroushani, A. R., Ahmadi, F., \& Ybarra, M. L. (2014). What sources do adolescents turn to for information about their health concerns? Int. Journal of Adolescents' Medicine and Health, 26(1), 61-68.

Bello, J., \& Owoaje, E. T. (2010). Psychoactive substances use among undergraduate students of the University of Ibadan, Nigeria. Tropical Journal of Health Sciences, 17(2), 40-46.

Chrea, C., Emilien, G., Salzberger, T., Cano, S., Alfieri, T., Mainy, N., \& Ludicke, F. (2015). Perceived risk instrument (PRI) to measure perceived risks associated with the use of nicotine and tobacco products. New York: Philip Morris International Research and Development.

Drug Abuse (2016, 12). The Effects of Cocaine Use. Retrieved from Drug Abuse: http://www.drugabuse.com/library/the-effects-of-cocaine-use.

Ek, S., \& Heinstrom, J. (2011). Monitoring or avoiding health information - the relation to inner inclination and health status. Health Information and Libraries Journal, 28, 200-209.

Ekpenyong, N. S., \& Aakpege, N. Y. (2014). Alcohol consumption pattern and risky behaviour: A study of university of Port-Harcourt. Journal of Humanities and Social Science (IOSR-JHSS), 19(2), 25-32. 
Fauzi, N., \& Abd Kadir, R. (2015). Information seeking behaviour of the adolescents with reference to sexual information. Procedia - Social and Behavioural Sciences, 211, 790-795.

Ford, N. (2015). Introduction to information behavior. London: Facet Publishing.

Institute of Medicine and National Research Council (2013). Examining a developmental approach to childhood obesity: The fetal and early childhood years: Workshop in brief. Washington, DC: The National Academies Press. McGuire, Shelley. American.

Johnson, O. E., Akpanekpo, E. I., Okonna, E. M., Adeboye, S. E., \& Udoh, A. J. (2017). The Prevalence and Factors affecting Psychoactive Substance Use among Undergraduate Students in University of Uyo, Nigeria. Journal of Community Medicine and Primary Health Care, 29(2), 11-22.

Johnston, L. D., O’Malley, P. M., Bachman, J. G., \& Schulenberg, J. E. (2012). Monitoring the future national survey results on drug use, 1975-2011 (1). Ann Arbor, MI: University of Michigan. Retrieved from http://monitoringthefuture.org/pubs/monographs/mtf-vol12011.pdf

Katzung, G. B. (2012). Basic and clinical pharmacology. New York: McGraw-Hill Companies, Inc.

National Drug Law Enforcement Agency. (2017). Drug data collection and research, Lagos. Lagos: National Drug Law Enforcement Agency (NDLEA) . Retrieved from National Drug Law Enforcement Agency (NDLEA) Website.

National Institute on Drug Abuse. (2015). Drugs of abuse: Opioids. Retrieved from National Institute on Drug Abuse Website: http://www.drugabuse.gov/drugs-abuse/opioids.

National Institute on Drug Abuse. (2015). Drugs of facts: Heroin. Retrieved from National Institute on Drug Abuse Website: http://www.drugabuse.gov/publications/drugsfacts/heroin.

Okoza, J., \& Aluede, O. (2009). Drug abuse among students of Ambrose Alli University, Ekpoma, Nigeria. European Journal of Sciences, 10(1), 85-92.

Omigbodun, O. O., \& Babalola, O. (2004). Review of psychosocial dynamics of psychoactive substances misuse among Nigerian adolescents. Annals of Africa Medicine, 3(3), 111 -115.

Onofa, L., Adamson, T., Ighoroje, M., \& Majekodunmi, M. (2016). Prevalence and pattern of drug abuse among students of three tertiary institutions in Abeokuta. International Journal of Psychiatry, l(1).

Pettigrew, K., Fidel, R., \& Bruce, H. (2001). Conceptual frameworks in information behaviour. Annual Review of Information Science and Technology, 35, 43-78.

Salzberger, T., \& Cano, S. (2017). The perception of Risk Instrument (PRI). Consumer perception of product risks and benefits. Springer, 201-219.

SAMHSA (2000). National household survey on drug abuse: Main Findings 1998. Rockville, MD,

Department of Health and Human Services, Substance Abuse and Mental Health Service Administration

Semulimi, A. W. (2017). The use of opioids, cocaine and cannabinoids among undergraduate students at Makerere University, Kampala. Retrieved from Research Gate Website: https://www.researchgate.net/publication/ 312159384

Sue, D., Sue, D. W., \& Sue, S. (2006). Models of abnormal behaviours, understanding abnormal behaviour (8th ed.). New York: Houghton Mifflin Company.

Uchendu, U. I., \& Ukornu, O. I. (2016). Effect of substance use on academic performance among undergraduate students in the University of Abuja, Nigeria. Journal of Research in Humanities and Social Science, 4(3), 62-71.

UNODC (2016). World DrugReport. Retrieved from UNODC Website: http://www.unodc.org/nigeria/en/drug prevention.html.

WebMD (2019). Schizophrenia and marijuana: Trigger or Treatment? https://www.webmd.com/schizophrenia/schizophrenia-marijuana-link\#1

Wilson, T. D. (2000). Human information behaviour. Information Science, 3(2), 49-56. 
Wilson, T. D. (2000). Recent trends in user studies: action research and qualitative methods. Information Research, 5, 3-5.

World Health Organization. (1987). WHO drug information. Proposed inn list 57 international nonproprietary names for pharmaceutical substances. Geneva: World Health Organization.

World Health Organization. (2016). World drug report 2016. Vienna: United Nations Office on Drugs and Crime.

World Health Organization. (2019). Tobacco. World Health Organisation. From: https://www.who.int/news-room/fact-sheets/detail/tobacco.Retrieved: July 9, 2019.

Yusuf, F. A. (2012). Factors Influencing substance abuse among undergraduate students in Osun State, Nigeria. African Research Review, 4(4). 